AAPS PharmSciTech 2004; 5 (2) Article 34 (http://www.aapspharmscitech.org).

\title{
Gastroretentive Drug Delivery System of Ranitidine Hydrochloride: Formulation and In Vitro Evaluation
}

Submitted: February 25, 2004; Accepted: April 8, 2004.

Brijesh S. Dave, ${ }^{1}$ Avani F. Amin, ${ }^{1}$ and Madhabhai M. Patel ${ }^{1}$

${ }^{1}$ Shree S. K. Patel College of Pharmaceutical Education \& Research, Ganpat Vidyanagar, India

\section{AbstraCt}

The purpose of this research was to prepare a gastroretentive drug delivery system of ranitidine hydrochloride. Guar gum, xanthan gum, and hydroxypropyl methylcellulose were evaluated for gel-forming properties. Sodium bicarbonate was incorporated as a gas-generating agent. The effects of citric acid and stearic acid on drug release profile and floating properties were investigated. The addition of stearic acid reduces the drug dissolution due to its hydrophobic nature. A $3^{2}$ full factorial design was applied to systemically optimize the drug release profile. The amounts of citric acid anhydrous $\left(\mathrm{X}_{1}\right)$ and stearic acid $\left(\mathrm{X}_{2}\right)$ were selected as independent variables. The times required for $50 \%\left(\mathrm{t}_{50}\right)$ and $80 \%$ drug dissolution $\left(t_{80}\right)$, and the similarity factor $f_{2}$ were selected as dependent variables. The results of the full factorial design indicated that a low amount of citric acid and a high amount of stearic acid favors sustained release of ranitidine hydrochloride from a gastroretentive formulation. A theoretical dissolution profile was generated using pharmacokinetic parameters of ranitidine hydrochloride. The similarity factor $\mathrm{f}_{2}$ was applied between the factorial design batches and the theoretical dissolution profile. No significant difference was observed between the desired release profile and batches F2, F3, F6, and F9. Batch F9 showed the highest $\mathrm{f} 2$ ( $\mathrm{f} 2=75$ ) among all the batches, and this similarity is also reflected in $t_{50}$ ( $\sim 214$ minutes) and $t_{80}(\sim 537$ minutes $)$ values. These studies indicate that the proper balance between a release rate enhancer and a release rate retardant can produce a drug dissolution profile similar to a theoretical dissolution profile.

KEYWORDS: ranitidine hydrochloride, gastroretentive, floating drug delivery, sustained release.

\section{INTRODUCTION}

Ranitidine hydrochloride ( $\mathrm{RHCl}$ ) is a histamine $\mathrm{H}_{2}$-receptor antagonist. It is widely prescribed in active duodenal ulcers, gastric ulcers, Zollinger-Ellison syndrome, gastroesophageal

Corresponding Author: Brijesh S. Dave, Shree S. K. Patel College of Pharmaceutical Education \& Research, Ganpat Vidyanagar, India. Tel: +91-2762-286082. Fax: +91-2762-286082. Email: brijesh_dave@yahoo.com. reflux disease, and erosive esophagitis. The recommended adult oral dosage of ranitidine is $150 \mathrm{mg}$ twice daily or 300 $\mathrm{mg}$ once daily. The effective treatment of erosive esophagitis requires administration of $150 \mathrm{mg}$ of ranitidine 4 times a day. ${ }^{1}$ A conventional dose of $150 \mathrm{mg}$ can inhibit gastric acid secretion up to 5 hours but not up to 10 hours. An alternative dose of $300 \mathrm{mg}$ leads to plasma fluctuations; thus a sustained release dosage form of $\mathrm{RHCl}$ is desirable. ${ }^{2}$ The short biological half-life of drug ( 2.5-3 hours) also favors development of a sustained release formulation.

A traditional oral sustained release formulation releases most of the drug at the colon, thus the drug should have absorption window either in the colon or throughout the gastrointestinal tract. Ranitidine is absorbed only in the initial part of the small intestine and has $50 \%$ absolute bioavailability. ${ }^{3,4}$ Moreover, colonic metabolism of ranitidine is partly responsible for the poor bioavailability of ranitidine from the colon. ${ }^{5}$ These properties of $\mathrm{RHCl}$ do not favor the traditional approach to sustained release delivery. Hence, clinically acceptable sustained release dosage forms of $\mathrm{RHCl}$ prepared with conventional technology may not be successful.

The gastroretentive drug delivery systems can be retained in the stomach and assist in improving the oral sustained delivery of drugs that have an absorption window in a particular region of the gastrointestinal tract. These systems help in continuously releasing the drug before it reaches the absorption window, thus ensuring optimal bioavailability.

It is also reported that oral treatment of gastric disorders with an $\mathrm{H}_{2}$-receptor antagonist like ranitidine or famotidine used in combination with antacids promotes local delivery of these drugs to the receptor of the parietal cell wall. Local delivery also increases the stomach wall receptor site bioavailability and increases the efficacy of drugs to reduce acid secretion. ${ }^{6}$ This principle may be applied for improving systemic as well as local delivery of RHCl, which would efficiently reduce gastric acid secretion.

Several approaches are currently used to prolong gastric retention time. These include floating drug delivery systems, also known as hydrodynamically balanced systems, swelling and expanding systems, polymeric bioadhesive systems, modified-shape systems, high-density systems, and other delayed gastric emptying devices. ${ }^{7,8}$ The principle of buoyant preparation offers a simple and practical approach to achieve 
AAPS PharmSciTech 2004; 5 (2) Article 34 (http://www.aapspharmscitech.org).

Table 1. Tablet Formulations for Preliminary Trials*

\begin{tabular}{lcccccccc}
\hline Ingredients & A1 & A2 & A3 & A4 & A5 & A6 & A7 & A8 \\
\hline HPMC K4 M, milligrams & - & - & 90 & 90 & 90 & 90 & 90 & 90 \\
Guar gum, milligrams & 90 & - & - & - & - & - & - & - \\
Xanthan gum, milligrams & - & 90 & - & - & - & - & - & - \\
NaHCO3, milligrams & 50 & 50 & 50 & 25 & 50 & 50 & 50 & 50 \\
Stearic acid, milligrams & - & - & - & - & 50 & 20 & 5 & 5 \\
Citric acid, milligrams & - & - & - & - & 10 & 10 & 10 & 20 \\
Floating lag time, seconds & No floating & 695 & 106 & 460 & 121 & 77 & 106 & 65 \\
$t_{50}$, minutes & - & - & 104 & 134 & 430 & 381 & 200 & 7 \\
\hline
\end{tabular}

*HPMC K4 M indicates hydroxypropyl methylcellulose. All batches contained 336 milligrams ranitidine hydrochloride, $1 \% \mathrm{wt} / \mathrm{wt}$ talc and $1 \% \mathrm{wt} / \mathrm{wt}$ magnesium stearate.

increased gastric residence time for the dosage form and sustained drug release.

In context of the above principles, a strong need was recognized for the development of a dosage form to deliver $\mathrm{RHCl}$ in the stomach and to increase the efficiency of the drug, providing sustained action. The present investigation applied a systematic approach to the development of gastroretentive $\mathrm{RHCl}$ dosage forms.

\section{MATERIALS ANd METHOdS}

\section{Materials}

Ranitidine hydrochloride was received as a gift sample from Cadila Pharmaceuticals Ltd, Ahmedabad, India. Hydroxypropyl methylcellulose (HPMC K4 M), guar gum, and xanthan gum were received as gift samples from Zydus-Cadila Healthcare Ltd, Ahmedabad, India. Sodium bicarbonate, stearic acid, and citric acid anhydrous (hereafter referred to as citric acid) were purchased from S.D. Fine-Chem Ltd, Ahmedabad, India. All other ingredients were of laboratory grade.

\section{Methods}

Preparation of Ranitidine Hydrochloride Floating Tablets (Preliminary Trials)

$\mathrm{RHCl}$ (336 mg equivalent to $300 \mathrm{mg}$ of ranitidine) was mixed with the required quantities of HPMC K4 M/guar gum/xanthan gum, sodium bicarbonate, and citric acid by geometric mixing. In batches A5 to A8 and factorial design batches ( $\mathrm{F} 1$ to $\mathrm{F} 9$ ), $\mathrm{RHCl}$ was dispersed in chloroformic solution of the required quantity of stearic acid. The dispersion was stirred and chloroform was evaporated to form an RHCl-stearic acid mixture. This mixture was then blended with other ingredients as described previously. The powder blend was then lubricated with magnesium stearate $(1 \%$ $\mathrm{wt} / \mathrm{wt})$ and purified talc $(1 \% \mathrm{wt} / \mathrm{wt})$ and compressed on single punch tablet machine (Cadmach, Ahmedabad, India).
The tablets were round and flat with an average diameter of $12 \pm 0.1 \mathrm{~mm}$ and a thickness of $4 \pm 0.2 \mathrm{~mm}$. The formulations of the preliminary trial batches (A1 to A8) are shown in Table 1. The formulations of the factorial design batches (F1 to F9) are shown in Table 2.

\section{In Vitro Buoyancy Studies}

The in vitro buoyancy was determined by floating lag time, per the method described by Rosa et $\mathrm{al}^{9}$ The tablets were placed in a $100-\mathrm{mL}$ beaker containing $0.1 \mathrm{~N} \mathrm{HCl}$. The time required for the tablet to rise to the surface and float was determined as floating lag time.

\section{In Vitro Dissolution Studies}

The release rate of $\mathrm{RHCl}$ from floating tablets $(\mathrm{n}=3)$ was determined using United States Pharmacopeia (USP) 24. Dissolution Testing Apparatus 2 (paddle method). The dissolution test was performed using $900 \mathrm{~mL}$ of $0.1 \mathrm{~N} \mathrm{HCl}$, at $37 \pm$ $0.5^{\circ} \mathrm{C}$ and $75 \mathrm{rpm}$. A sample $(10 \mathrm{~mL})$ of the solution was withdrawn from the dissolution apparatus hourly for 12 hours, and the samples were replaced with fresh dissolution medium. The samples were filtered through a $0.45-\mu$ membrane filter and diluted to a suitable concentration with $0.1 \mathrm{~N} \mathrm{HCl}$. Absorbance of these solutions was measured at $315 \mathrm{~nm}$ using a Shimadzu UV-1601 UV/Vis double-beam spectrophotometer (Kyoto, Japan). Cumulative percentage drug release was calculated using an equation obtained from a standard curve. The times for $50 \%$ and $80 \%$ drug release were calculated based on the Korsemeyer and Peppas model. ${ }^{10}$

\section{Full Factorial Design}

A $3^{2}$ randomized full factorial design was used in this study. In this design 2 factors were evaluated, each at 3 levels, and experimental trials were performed at all 9 possible combi- 
AAPS PharmSciTech 2004; 5 (2) Article 34 (http://www.aapspharmscitech.org).

Table 2. Formulation and Dissolution Characteristics of Batches in a $3^{2}$ Full Factorial Design*

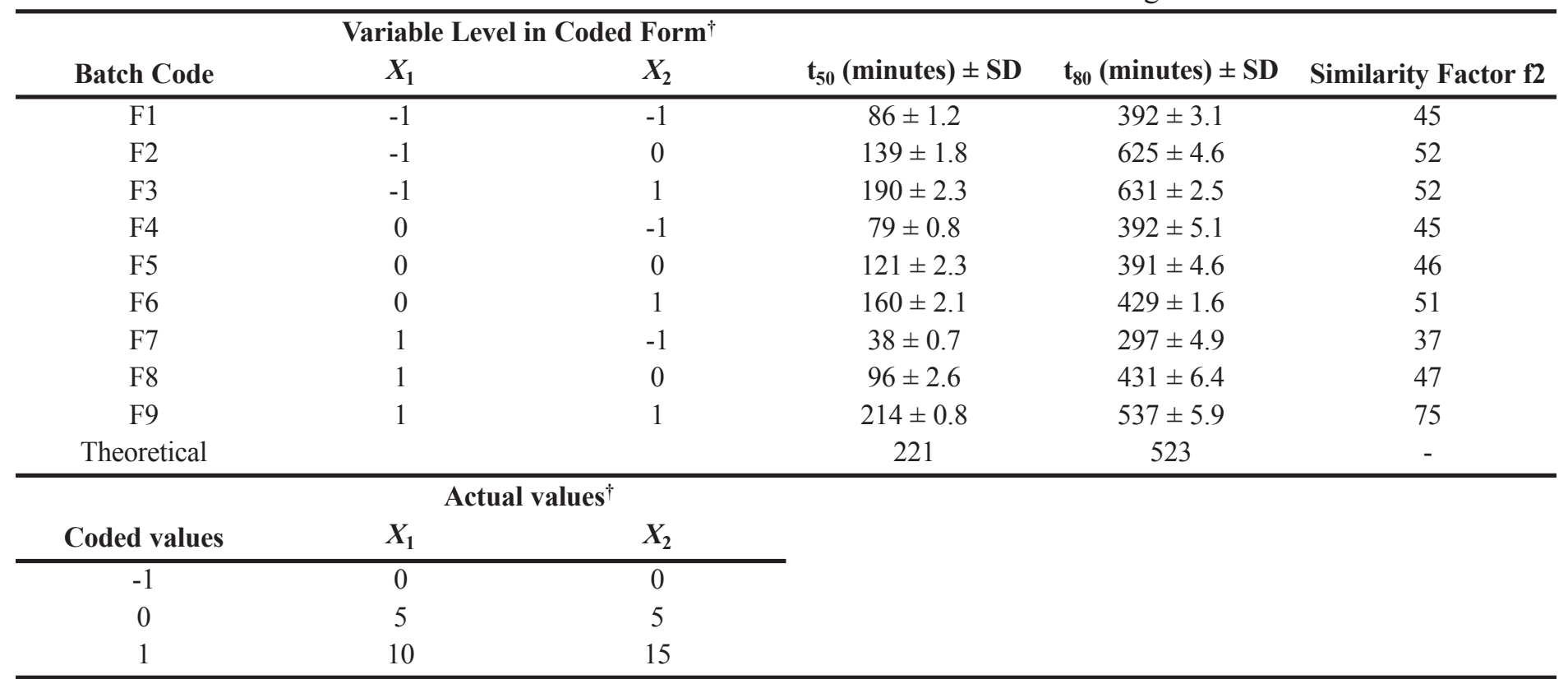

*All batches contained $336 \mathrm{mg}$ ranitidine hydrochloride, $50 \mathrm{mg}$ sodium bicarbonate, $1 \% \mathrm{wt} / \mathrm{wt}$ talc, and 1\% wt/wt magnesium stearate.

${ }^{\dagger} X_{1}$ is amount of citric acid in milligrams; $X_{2}$ is amount of stearic acid in milligrams

nations. The amounts of citric acid anhydrous $\left(\mathrm{X}_{1}\right)$ and stearic acid $\left(\mathrm{X}_{2}\right)$ were selected as independent variables. The times required for $50 \%$ and $80 \%$ drug dissolution, and the similarity factor $\mathrm{f} 2$ were selected as dependent variables.

\section{Kinetic Modeling of Drug Release}

The dissolution profile of all the batches was fitted to zeroorder, first-order, ${ }^{11,12}$ Higuchi, ${ }^{13-15}$ Hixon-Crowell, ${ }^{16}$ Korsemeyer and Peppas, ${ }^{10,17,18}$ and Weibull models ${ }^{19-22}$ to ascertain the kinetic modeling of drug release. The method of Bamba et al was adopted for deciding the most appropriate model. ${ }^{23}$

\section{RESULTS AND DISCUSSION}

\section{In Vitro Buoyancy Studies}

Noneffervescent floating drug delivery was used to achieve in vitro buoyancy. In the initial batches, $\mathrm{RHCl}$ tablets prepared using polymers such as HPMC K4 M, guar gum, and xanthan gum did not exhibit sufficient swelling to provide in vitro buoyancy. An effervescent approach was then adopted. Three batches (A1 to A3) were prepared using guar gum, xanthan gum, and HPMC K4 M, respectively; sodium bicarbonate was added as a gas-generating agent. Sodium bicarbonate induced $\mathrm{CO}_{2}$ generation in the presence of dissolution medium $(0.1 \mathrm{~N}$ $\mathrm{HCl})$. The gas generated is trapped and protected within the gel, formed by hydration of polymer, thus decreasing the density of the tablet. As the density of the tablet falls below 1, the tablet becomes buoyant. Whitehead et al have demonstrated good correlation between in vitro and in vivo buoyancy of floating dosage forms. ${ }^{24}$ Batches A1 and A2, containing guar gum and xanthan gum, failed to form a gel with sufficient strength, while A3 with HPMC K4 M produced tablets with good gel strength, entrapping $\mathrm{CO}_{2}$ gas and imparting stable and persistent buoyancy. To study the effect of sodium bicarbonate concentration on floating lag time, batch A4 was formulated. The results, shown in Table 1, demonstrate that as the amount of sodium bicarbonate decreases, the floating lag time increases. Thus, sodium bicarbonate (50 mg per tablet) was essential to achieve optimum in vitro buoyancy.

\section{In Vitro Dissolution Studies}

Since the $\mathrm{pH}$ of stomach is elevated under fed condition $(\sim 3.5)$, citric acid was incorporated in the formulation to provide an acidic medium for sodium bicarbonate. Moreover, citric acid has a stabilizing effect on $\mathrm{RHCl}$ formulations. ${ }^{25}$ However, because adding citric acid to the formulation might enhance dissolution, stearic acid was incorporated in the formulations to sustain drug release. Batches A5 to A7 were formulated to study the effect of stearic acid concentration on release profile. In batch $\mathrm{A} 8$, the concentration of citric acid was increased. The pharmacokinetic parameters ${ }^{1,3,4}$ of $\mathrm{RHCl}$ were used to calculate a theoretical drug release profile for a 12-hour dosage form. The immediate release part for sustained-release $\mathrm{RHCl}$ was calculated using Equation 1 and was found to be $96.53 \mathrm{mg}$.

$$
\text { Immediate release part }=(C s s \times V d) / F \text {, }
$$


where Css is steady-state plasma concentration (Average $\mathrm{C}_{\max }$ ), $V d$ is volume of distribution, and $F$ is fraction bioavailable.

Hence, the formulation should release $96.53 \mathrm{mg}$ (32.17\%) of drug in 1 hour like conventional tablets and $18.5 \mathrm{mg}(6.16 \%)$ per hour up to 12 hours thereafter. The $t_{50}$ of the theoretical dissolution profile is 221 minutes. The $t_{50}$ of batches A5 to A8 varied from the theoretical $t_{50}$ (Table 1). Incorporation of citric acid reduced floating lag time but caused tablet erosion.

\section{Factorial Design}

A $3^{2}$ full factorial design was constructed to study the effect of the amount of citric acid $\left(\mathrm{X}_{1}\right)$ and the amount of stearic acid $\left(\mathrm{X}_{2}\right)$ on the drug release from gastroretentive $\mathrm{RHCl}$ tablets. The dependent variables chosen were times required for $50 \%$ and $80 \%$ drug dissolution, and similarity factor $\mathrm{f} 2$ (average dissolution profile with theoretical release profile).

A statistical model incorporating interactive and polynomial terms was utilized to evaluate the response.

$$
Y=b_{0}+b_{1} X_{1}+b_{2} X_{2}+b_{12} X_{1} X_{2}+b_{11} X_{1}^{2}+b_{22} X_{2}^{2},
$$

where $Y$ is the dependent variable, $b_{0}$ is the arithmetic mean response of the 9 runs, and $b_{\mathrm{i}}$ is the estimated coefficient for the factor $X_{\mathrm{i}}$. The main effects $\left(X_{1}\right.$ and $\left.X_{2}\right)$ represent the average result of changing one factor at a time from its low to high value. The interaction terms $\left(X_{1} X_{2}\right)$ show how the response changes when 2 factors are changed simultaneously. The polynomial terms $\left(X_{1}^{2}\right.$ and $\left.X_{2}^{2}\right)$ are included to investigate nonlinearity. The statistical analysis of the factorial design batches was performed by multiple linear regression analysis using Microsoft Excel. The $t_{50}, t_{80}$, and $\mathrm{f} 2$ values for the 9 batches (F1 to F9) showed a wide variation; the results are shown in Table 2. The data clearly indicate that the values of $t_{50}, t_{80}$, and $f 2$ are strongly dependent on the independent variables. The fitted equations relating the response $t_{50}$, $\mathrm{t}_{80}$, and $\mathrm{f} 2$ to the transformed factor are shown in Equation 3, Equation 4, and Equation 5, respectively.

$$
\begin{aligned}
& \mathrm{t}_{50}=114.189-11.231 X_{1}+60.333 X_{2}+ \\
& 17.940 X_{1} X_{2}+6.96 X_{1}^{2}+9.054 X_{2}^{2} \\
& \left(R^{2}=0.9391\right) \\
& \mathrm{t}_{80}=428.145-63.728 X_{1}+85.991 X_{2}+ \\
& 0.173 X_{1} X_{2}+81.404 X_{1}^{2}-36.128 X_{2}^{2} \\
& \left(R^{2}=0.8094\right) \\
& \mathrm{f} 2=45.666+1.666 X_{1}+8.5 X_{2}+7.75 \\
& X_{1} X_{2}+4 \underline{X}_{1}^{2}+2.5 X_{2}^{2} \\
& \left(R^{2}=0.8370\right)
\end{aligned}
$$

The values of the correlation coefficient indicate a good fit. The polynomial equation can be used to draw conclusions after considering the magnitude of coefficient and the mathematical sign it carries, (ie, positive or negative).

Figures 1 and 2 show the plot of the amount of citric acid $\left(X_{1}\right)$ and amount of stearic acid $\left(X_{2}\right)$ versus $t_{50}$ and $t_{80}$, respectively. The plot was drawn using Sigma Plot software (Jandel Scientific Software, San Rafael, CA). The data demonstrate that both $X_{1}$ and $X_{2}$ affect the drug release $\left(\mathrm{t}_{50}\right.$ and $\left.\mathrm{t}_{80}\right)$. It may also be concluded that the low level of $X_{1}$ (amount of citric acid) and the higher level of $X_{2}$ (amount of stearic acid) favor the preparation of gastroretentive sustained release $\mathrm{RHCl}$ tablets. The high value of $X_{1} X_{2}$ coefficient also suggests that the interaction between $X_{1}$ and $X_{2}$ has a significant effect on $t_{50}$. It can be concluded that the drug release pattern may be

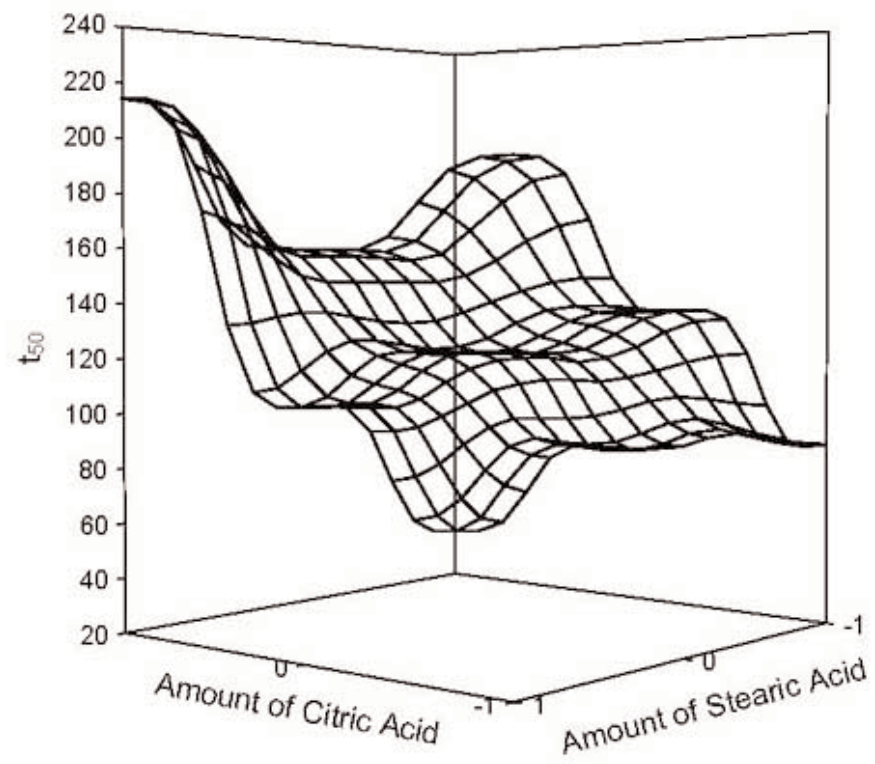

Figure 1. Response surface plot for $t_{50}$.

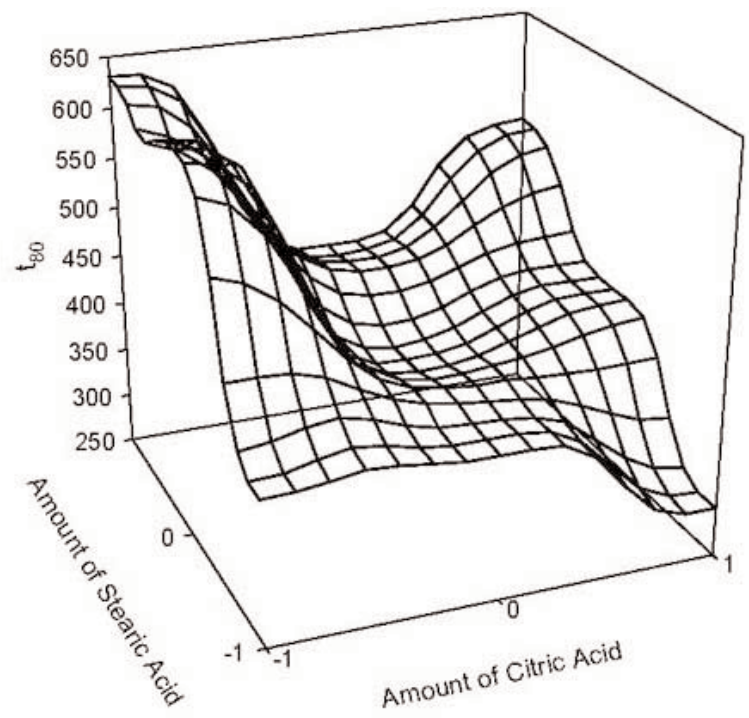

Figure 2. Response surface plot for $t_{80}$. 
changed by appropriate selection of the $X_{1}$ and $X_{2}$ levels. The results in Table 2 reveal that batches $\mathrm{F} 3$ and $\mathrm{F} 9$ were close to theoretical $\mathrm{t}_{50}$, while $\mathrm{F} 9$ was the only batch that was similar to theoretical $t_{80}$.

The similarity factor, f2, given by Scale Up and Pose Approval Changes (SUPAC) guidelines for modified release dosage form was used as a basis to compare dissolution profiles. ${ }^{26}$ The dissolution profiles are considered to be similar when $\mathrm{f} 2$ is between 50 and 100 . The method was first reported by Moore and Flanner. ${ }^{27}$

The results in Table 2 indicate that batches F2, F3, F6, and F9 fulfill the above criteria. But batch F9 showed the highest $\mathrm{f} 2$ among all the batches, and this similarity is also reflected in $t_{50}$ and $t_{80}$ values. The $f 2$ value of 75 of batch F9 indicates less than $5 \%$ difference in dissolution profiles. The similarity between the theoretical dissolution profile and the dissolution profile of F9 is clearly demonstrated in Figure 3.

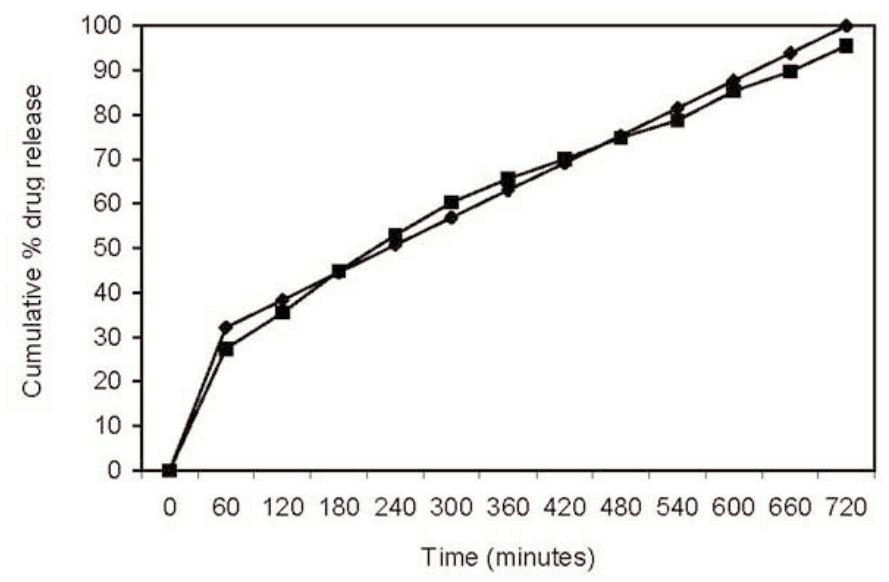

Figure 3. Comparison of in vitro dissolution profiles of batch F9 and theoretical dissolution profile: $\bullet$ indicates theoretical dissolution profile; $\boldsymbol{\nabla}$ indicates F9.

\section{In Vitro Buoyancy of Factorial Design Batches}

All the factorial design batches showed good in vitro buoyancy. The results of the in vitro buoyancy study of batch F9 are shown in Figure 4 . The figure clearly indicates the floating lag time ( 2 minutes) of the $\mathrm{RHCl}$ tablets and the floating and swelling tendency of the formulation. The tablet swelled radially and axially. The average radial diameter after 8 hours was $15 \pm 0.3 \mathrm{~mm}$, while the thickness was $7.5 \pm 0.4 \mathrm{~mm}$. The figure also indicates that the tablet remained buoyant for 8 hours, but the tablet actually floated throughout the entire study. The in vitro buoyancy study was also conducted at an elevated $\mathrm{pH}$ condition ( 4.5). The floating tendency remained unaltered at higher $\mathrm{pH}$.

\section{Kinetics of Drug Release}

The dissolution data of batches F1 to F9 was fitted to zeroorder, first-order, Higuchi, Hixson-Crowell, Korsemeyer and Peppas, and Weibull models. The method of Bamba et al was adopted for deciding the most appropriate model. ${ }^{23}$ The results of $F$-statistics were used to select the most appropriate model. The release profile of the best batch, F9, fitted best to the Korsemeyer and Peppas model $(F=1.65)$. This superiority is statistically insignificant with the Higuchi model $(F=1.86)$, but significant with the Weibull model $(F=17.4)$ as shown by the goodness-of-fit test ( $F$ ratio test). But priority should be given to the model with the lowest $F$ value. Thus, it may be concluded that drug release from gastroretentive $\mathrm{RHCl}$ tablets is best explained by the Korsemeyer and Peppas model. The values of slope and intercept for the Korsemeyer and Peppas model are 0.5105 and -1.4906, respectively. The value of the slope indicates that the drug released by diffusion of an anomalous type. However, batches F1 to F8 followed the Korsemeyer and Peppas model for drug release but showed nonanomalous diffusion.
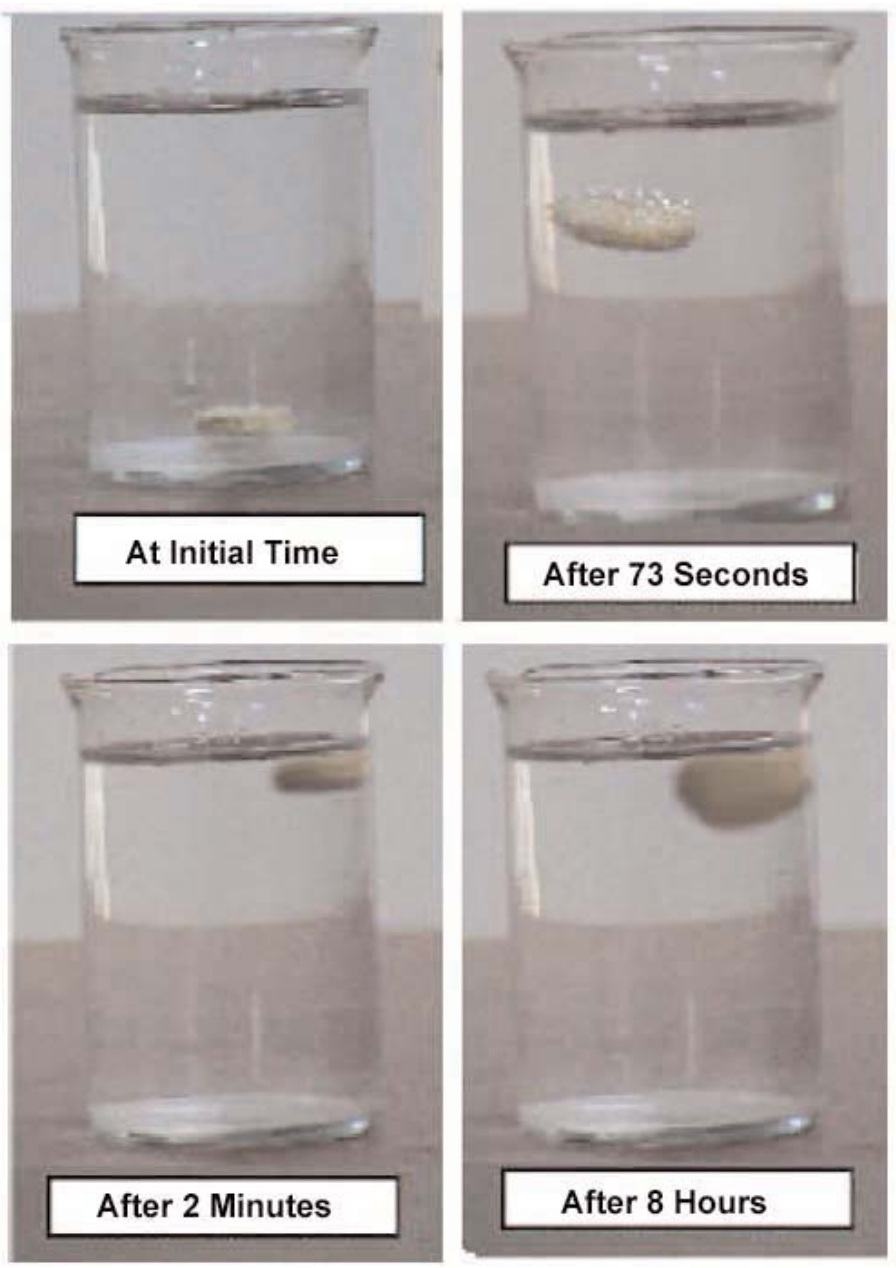

Figure 4. In vitro buoyancy study of batch F9. 


\section{CONCLUSION}

This study discusses the preparation of gastroretentive tablets of RHCl. The effervescent-based floating drug delivery was a promising approach to achieve in vitro buoyancy. The addition of gel-forming polymer HPMC K4 M and gas-generating agent sodium bicarbonate was essential to achieve in vitro buoyancy. Addition of citric acid, to achieve buoyancy under the elevated $\mathrm{pH}$ of the stomach, caused an enhancement in drug release that was retarded by incorporation of stearic acid in the formulation. A systematic study using a $3^{2}$ full factorial design revealed that the amount of citric acid and stearic acid had a significant effect on $\mathrm{t}_{50}, \mathrm{t}_{80}$, and $\mathrm{f} 2$. Thus, by selecting a suitable composition of release rate enhancer (citric acid) and release rate retardant (stearic acid), the desired dissolution profile can be achieved.

\section{REFERENCES}

1. Histamine H2 antagonists. In: Drug Facts and Comparisons. 16th ed. St Louis, MO: Wolters Kluwer Co; 1996:1862-1876.

2. Somade S, Singh K. Comparative evaluation of wet granulation and direct compression methods for preparation of controlled release Ranitidine HCL tablets. Indian J Pharm Sci. 2002;64:285.

3. Lauritsen K. Clinical pharmacokinetics of drugs used in the treatment of gastrointestinal diseases. Clin Pharmacokinet. 1990;19:11-31, 94-125.

4. Grant S. Ranitidine: an updated review of its pharmacodynamic and pharmacokinetic properties and therapeutic use in peptic ulcer and other allied diseases. Drugs. 1989;37:801-870.

5. Basit A, Lacey L. Colonic metabolism of ranitidine: implications for its delivery and absorption. Int J Pharm. 2001;227(1-2):157-165.

6. Coffin M, Parr A. Ranitidine solid dosage form. US Patent 5407687. April 18, 1995.

7. Singh B, Kim K. Floating drug delivery systems: an approach to oral controlled drug delivery via gastric retention. J Control Release. 2000;63:235-259.

8. Chawla G, Bansal A. A means to address regional variability in intestinal drug absorption. Pharm Tech. 2003;27:50-68.

9. Rosa M, Zia H, Rhodes T. Dosing and testing in-vitro of a bioadhesive and floating drug delivery system for oral application. Int J Pharm. 1994;105:65-70.

10. Korsemeyer R, Gurny R, Peppas N. Mechanisms of solute release from porous hydrophilic polymers. Int J Pharm. 1983;15:25-35.
11. Wagner JG. Interpretation of percent dissolved-time plots derived from in vitro testing of conventional tablets and capsules. J Pharm Sci. 1969;58:1253-1257.

12. Gibaldi M, Feldman S. Establishment of sink conditions in dissolution rate determinations: theoretical considerations and application to nondisintegrating dosage forms. J Pharm Sci. 1967;56:1238-1242.

13. Higuchi T. Rate of release of medicaments from ointment bases containing drugs in suspension. J Pharm Sci. 1961;50:874-875.

14. Higuchi T. Mechanism of sustained-action medication: theoretical analysis of rate of release of solid drugs dispersed in solid matrices. $J$ Pharm Sci. 1963;52:1145-1149.

15. Cobby J, Mayersohn M, Walker GC. Influence of shape factors on kinetics of drug release from matrix tablets. II. Experimental. J Pharm Sci. 1974;63:732-737.

16. Hixson AW, Crowell JH. Dependence of reaction velocity upon surface and agitation. Ind Eng Chem. 1931;23:923-931.

17. Peppas NA. Analysis of Fickian and non-Fickian drug release from polymers. Pharm Acta Helv. 1985;60:110-111.

18. Harland RS, Gazzaniga A, Sangalli ME, Colombo P, Peppas NA. Drug/polymer matrix swelling and dissolution. Pharm Res. 1988;5:488-494.

19. Langenbucher F. Linearization of dissolution rate curves by the Weibull distribution. J Pharm Pharmacol. 1988;24:979-981.

20. Goldsmith JA, Randall N, Ross SD. On methods of expressing dissolution rate data. J Pharm Pharmacol. 1978;30:347-349.

21. Romero P, Costa JB, Chulia D. Statistical optimization of a controlled release formulation obtained by a double compression process: application of a Hadamard matrix and a factorial design. In: Wells JI, Rubinstein MH, Horwood E, eds. Pharmaceutical Technology, Controlled Drug Release. Vol 2. New York, NY: Ellis Harwood; 1991:44-58.

22. Vudathala GK, Rogers JA. Dissolution of fludrocortisone from phospholipid coprecipitates. J Pharm Sci. 1992;81(3):282-286.

23. Bamba M, Puisieusx F. Release mechanisms in gel forming sustained release preparation. Int J Pharm. 1979;2:307-315.

24. Whitehead L, Fell J, Collett J, Sharma H, Smith A. Floating dosage forms: an in vivo study demonstrating prolonged gastric retention. $J$ Control Release. 1998;55:3-12.

25. Eyjolfsson R. Ranitidine $\mathrm{HCl}$ : tablet film coating acidity and discoloration. Drug Dev Ind Pharm. 2000;26:693-694.

26. Guidance for Industry SUPAC-MR. Modified Release Solid Oral Dosage Forms Scale-Up and Postapproval Changes: Chemistry, Manufacturing, and Controls; In Vitro Dissolution Testing and In Vivo Bioequivalence Documentation. Available at: http://www.fda.gov/cder/ guidance/index.htm.

27. Moore J, Flanner H. Mathematical comparison of dissolution profiles. Pharm Tech. 1996;20:64-74. 